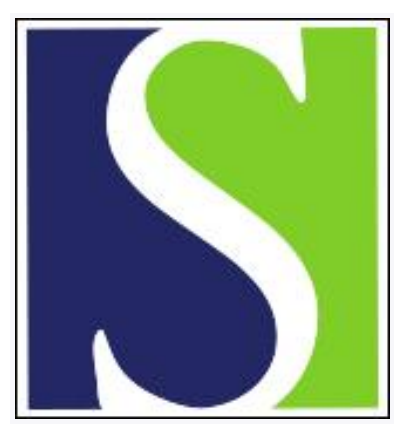

Scand J Work Environ Health 2002;28(3):168-175

https://doi.org/10.5271/sjweh.661

Issue date: Jun 2002

Physical workload of student nurses and serum markers of collagen metabolism

by Kuiper JI, Verbeek JHAM, Straub JP, Everts V, Frings-Dresen MHW

Affiliation: Coronel Institute for Occupational and Environmental Health, AmCOGG Amsterdam Center for Research into Health and Health Care, Academic Medical Center, University of Amsterdam, Amsterdam, Netherlands.

Refers to the following texts of the Journal: 1997;23(4):243-256 1998;24(6):449-464

Key terms: back disorder; collagen metabolism; connective tissue; patient handling; physical workload; prospective cohort study; serum marker; spine; student nurse

This article in PubMed: www.ncbi.nlm.nih.gov/pubmed/12109556

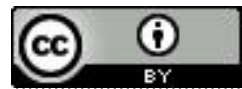




\title{
Physical workload of student nurses and serum markers of collagen metabolism
}

\author{
by Judith I Kuiper, PhD, ${ }^{1}$ Jos HAM Verbeek, PhD, ${ }^{1}$ Jan P Straub, MSc, ${ }^{1}$ Vincent Everts, PhD, ${ }^{2}$ Monique \\ HW Frings-Dresen, $P h D^{1}$
}

\begin{abstract}
Kuiper JI, Verbeek JHAM, Straub JP, Everts V, Frings-Dresen MHW. Physical workload of student nurses and serum markers of collagen metabolism. Scand J Work Environ Health 2002;28(3):168-175.
\end{abstract}

\begin{abstract}
Objectives This study explored the association between biomarkers of type I collagen metabolism and exposure to physical workload.

Methods In a prospective cohort study, serum concentrations of markers of type I collagen synthesis and degradation were assessed monthly for student nurses who worked as nurses for a period of 6 months and compared with those of a reference group. The number of patient-handling activities was estimated from observations at the workplace. Linear generalized estimating equations were used to analyze differences in the serum concentrations of the biomarkers between the exposed group and reference group, as well as to analyze whether the number of patient-handling activities was associated with serum concentrations of the biomarkers. Results Serum concentrations of the biomarkers were found to differ between the groups. The biomarkers reflected a higher anabolism of type I collagen in the exposed group when compared with that of the reference group. An analysis of the effect of the number of patient-handling activities revealed that a higher exposure was associated with higher effective type I collagen synthesis within the exposed group.

Conclusions These results indicate that serum concentrations of these biomarkers of type I collagen metabolism can reflect differences in exposure between contrasting groups, and also varying levels of exposure between persons within an occupation.
\end{abstract}

Key terms back disorders, collagen, connective tissues, patient handling, prospective cohort study, spine.

Reviews of the epidemiologic evidence on work-related risk factors for back disorders concluded that evidence exists showing that physical demands of work (manual materials handling, bending and twisting, and heavy physical load) can be associated with the occurrence or aggravation of low-back symptoms (1-5). However, evidence on causal relationships remains inconclusive due to the lack of knowledge as to the biological relevance of different load parameters and the large variability in susceptibility between persons. Although methods and strategies to assess external exposure accurately and biomechanical models to estimate the response of the tissues to these exposures have been developed $(6,7)$, very little is known about biologically effective doses and early biological effects in vivo. For a better understanding of the pathomechanisms of back disorders, and a definition of adequate parameters of exposure and effect, knowledge of the effects of load is essential at the tissue level. As indicators of processes at a molecular level, biomarkers may provide an objective, quantitative measure of the response of the structures in the back to physical load. Unfortunately, no validated biomarkers are yet available for assessing the effects of back load.

1 Coronel Institute for Occupational and Environmental Health, AmCOGG Amsterdam Center for Research into Health and Health Care, Academic Medical Center, University of Amsterdam, Amsterdam, The Netherlands.

2 Department of Cell Biology and Histology, Academic Medical Center, University of Amsterdam, The Netherlands and Department of Periodontology, Academic Center for Dentistry Amsterdam, University of Amsterdam, Amsterdam, The Netherlands.

Reprint requests to: Dr Jos HAM Verbeek, Coronel Institute for Occupational and Environmental Health, Academic Medical Center, University of Amsterdam, PO Box 22700, 1100 DE Amsterdam, The Netherlands. [E-mail: j.h.verbeek@amc.uva.nl] 
Because of the complex anatomy of the back and the multifactorial etiology of back disorders, it is complicated to identify relevant biomarkers. Physical load has been shown to cause responses in the spinal structures leading to changes in the metabolism of the extracellular matrix of connective tissues (8); therefore it is hypothesized that matrix metabolites in blood may provide potential biomarkers of the biological effects of physical back load on these structures. In connective tissues the extracellular matrix is responsible for the overall structural integrity of the tissue. When the level of load is slowly increased, the result may be an adaptive remodeling of the tissues. However, if the increase in load is sudden or large, the cells may not adapt quickly enough, and damage may result (9). Several laboratory assays have been developed to measure different matrix metabolites in blood to monitor metabolic alterations in connective tissues. In recent years, commercially available assays to measure type I collagen turnover have received considerable research attention as biomarkers for the effects of pathological processes and physical exercise on various connective tissues. Synthesis can be assessed by analyzing serum concentrations of carboxyterminal propeptide of type I collagen (PICP), whereas breakdown can be detected by analyzing carboxyterminal telopeptide region of type I collagen (CTx) (10). The ratio between PICP and CTx provides an estimate of type I collagen metabolism as a dynamic process of synchronously occurring anabolic and catabolic effects.

Type I collagen is one of the main constituents of the extracellular matrix of most connective tissues, it is tensile in nature and is found particularly in tissues subjected to tension and compression, like tendon, bone, and the anulus fibrosus of the intervertebral disc. Because of the widespread appearance of type I collagen in the human body, essentially, serum concentrations of markers of type I collagen metabolism may originate from various tissues. However, if it is assumed that collagen metabolism is not significantly altered in unaffected tissues, changes in serum concentrations of these biomarkers may provide relatively site-specific information when assessed in combination with appropriate exposure information. PICP and CTx have been used to investigate the effect of physical loading on various connective tissues induced by exercise (11-18) and active back rehabilitation (19).

To explore PICP and CTx as potential biomarkers of the effects physical demands of work, we investigated the association between these biomarkers and exposure to work involving heavy manual materials handling. The objective of the study was to determine whether serum concentrations of PICP and CTx in young nurses and the PICP : CTx ratio differ from those of a sedentary reference group during a 6-month period. Further- more, we investigated whether differences in exposure to patient-handling activities within the exposed group were associated with serum concentrations of PICP and CTx and their ratio.

\section{Subjects and methods}

\section{Design and study population}

A prospective cohort study was performed among student nurses during a 6-month work-placement period at the end of their vocational training. Apart from earlier short work-placement periods in the 4-year training program, this was the first period in which the student nurses performed nursing work for a long time at one stretch, for 4 days a week. Students were invited to participate if they had not had a job prior to the start of their vocational training. A total of 30 student nurses participated (3 men and 27 women). The participants went to different hospital departments, 10 in the internal medicine department, 7 in the surgery department, 6 in the obstetrics and gynecology department, 4 in the pediatric department, and 3 in the orthopedics department. Except for two participants, who worked in regional hospitals, all the participants worked in an academic hospital.

A reference group of 30 students ( 2 men and 28 women) was recruited among student nurses in the first year of their vocational training, when they had mostly theoretical education.

Once every month, starting the week before the work-placement period until 1 month after the end of the period, the participants visited our institute to donate a blood sample and to complete a questionnaire (time $0-7$ months in figure 1). The reference group did not donate blood on the eighth occasion (at 7 months) because they had started to participate in a short workplacement period by then. Individual characteristics such as age, height, and weight were assessed using data from the baseline questionnaire. Furthermore, the subjects were asked about the use of medication and whether they suffered or had suffered from musculoskeletal traumas in the previous year or from joint diseases, liver or kidney diseases, blood diseases, or metabolic

\begin{tabular}{|c|c|c|c|c|c|cc|}
\multicolumn{7}{c|}{ work-placement period } \\
Oct & Nov & Dec & Jan & Feb & March & April & May \\
\hline$\downarrow$ & $\downarrow$ & $\downarrow$ & $\downarrow$ & $\downarrow$ & $\downarrow$ & $\downarrow$ & $\downarrow$ \\
s0 & s1 & s2 & s3 & s4 & s5 & s6 & s7
\end{tabular}

Figure 1. Outline of the experimental design. (s= sample) 
diseases (like diabetes), because of the potentially confounding effect on the serum concentrations of the collagen markers. Table 1 presents the characteristics of the study population. The participants were fully informed about the procedures and filled out an informed consent form. The study was approved by the Ethics Committee of the Academic Medical Center, University of Amsterdam, The Netherlands.

\section{Assessment of physical load}

Exposure to patient-handling activities during the workplacement period was estimated by means of onsite observations using TRAC (Task Recording and Analysis on Computer) software (20). Each student nurse was observed for a full dayshift in the third or fourth month of the work-placement period. The frequency and duration of activities involving patient handling were observed on a real-time basis. These activities were divided into lifting patients, moving patients around in bed, transferring patients from bed to (wheel)chair and vice versa, pushing or pulling a wheelchair or bed containing a patient.

Changes in exposure to physical load during the work-placement period were assessed using the monthly questionnaire. Apart from the number of shifts they had worked per week, the student nurses were asked to estimate the percentage of worktime they had actually performed tasks as opposed to observing senior nurses and taking breaks.

To estimate exposure to physical load during leisure time, all the subjects were asked whether they had had side jobs, and, if so, for how many hours during the preceding month. On the basis of the job title, the jobs were classified as either physically demanding or not (21). Furthermore, the subjects reported whether they had been engaged in physically demanding sports and other leisure-time activities during the preceding month, and, if so, for how many hours.

\section{Exposure characteristics of the study population}

The results of the workplace observations showed that the average duration of a dayshift was 8 hours and 7 (SD 27) minutes. The student nurses lifted 5 (SD 7) pa- tients per shift. Moving patients around in bed averaged 1 (SD 2) times per day. The average frequency of pushing or pulling a bed or a wheelchair with a patient was 7 (SD 7) times and 2 (SD 3) times per shift, respectively, with an average duration of 4.4 (SD 5.5) minutes and 21 (SD 40) seconds per shift, respectively.

In the first month of the work-placement period, the exposed subjects spent an average of 46 (SD 17)\% of their worktime performing tasks themselves; this percentage increased to 67 (SD 17)\% in the second month. In the last 4 months the average percentage gradually increased from 74 (SD 15)\% in the third month to 80 (SD 10)\% in the final month.

At the different time points during the study period, the average number of hours worked in physically demanding side jobs ranged from 13 to 19 hours per month in the exposed group and from 13 to 16 hours per month in the reference group. The average number of hours spent on weight-bearing sports or leisure-time activities ranged from 4 to 10 hours per month in the exposed group and from 4 to 9 hours per month in the reference group.

\section{Biomarkers}

Blood samples of $7 \mathrm{ml}$ were collected by means of venipuncture in the anticubital vein. To minimize the possible effect of circadian rhythmicity, repeated blood samples were drawn at about the same time of day. After coagulation, the blood was centrifuged, and serum was stored at $-20{ }^{\circ} \mathrm{C}$ until analyzed. The serum concentrations of PICP were measured by the Prolagen-C sandwich enzyme-linked immunosorbent assay (ELISA) (Metra Biosystems, Mountain View, United States). The CTx serum concentrations were analyzed using the serum CrossLaps ${ }^{\mathrm{TM}}$ One Step ELISA (OSTEOMETER, Herlev, Denmark) (22). All of the samples of each subject were analyzed with the same kit, with the subjects of both study groups randomly divided over 16 kits of each of the assays. All of the samples were analyzed in duplicate. The intraassay precision (coefficient of variation) was $3.5 \%$ for PICP and $5.1 \%$ for CTx, whereas the interassay coefficients of variation were $9.6 \%$ and $10.7 \%$, respectively. To illustrate the effective change in collagen metabolism, the PICP:CTx ratio was calculated for each subject.

Table 1. Characteristics of study population.

\begin{tabular}{|c|c|c|c|c|c|c|c|c|}
\hline \multirow[b]{2}{*}{ Group } & \multicolumn{2}{|c|}{ Age (years) } & \multicolumn{2}{|c|}{ Height (meters) } & \multicolumn{2}{|c|}{ Weight (kilograms) } & \multicolumn{2}{|c|}{ Body mass index $\left(\mathrm{kg} / \mathrm{m}^{2}\right)$} \\
\hline & Mean & SD & Mean & SD & Mean & SD & Mean & SD \\
\hline Exposed a $(\mathrm{N}=30)$ & 22.4 & 1.9 & 1.73 & 0.07 & 65.5 & 7.8 & 21.8 & 2.0 \\
\hline Reference $^{b}(\mathrm{~N}=30)$ & 18.3 & 1.4 & 1.72 & 0.07 & 66.3 & 11.2 & 22.4 & 3.3 \\
\hline
\end{tabular}

a 3 men, 27 women. $\quad$ b 2 men, 28 women. 


\section{Statistical analysis}

The statistical analyses consisted of several steps. To test for baseline differences in the serum concentrations of the biomarkers between the groups, analyses of variance were performed for each of the biomarker parameters. To determine whether the serum concentrations of the biomarkers during the work-placement period differed between the exposed and reference groups, linear generalized estimating equations (GEE) were used (23). A GEE analysis accounts for the within-subject correlations between repeated measurements. Both time-dependent and time-independent covariates can be analyzed. Use of the GEE provides a pooled analysis of between-subject and within-subject associations (24). Separate analyses were performed with PICP and CTx concentrations and the PICP : CTx ratio during the workplacement period (time 1-6 months) as the time-dependent outcome variable and group and time (exact number of days) as the determinants. The interactions of "group $\times$ time" and "gender $\times$ group" were examined; if not significant, the interaction term was removed from the model.

Subanalyses were performed for the exposed group on the associations between the serum concentrations of each of the biomarkers and exposure to patient-handling activities. For each of the three biomarker parameters, a GEE analysis was conducted with the biomarker values during the work-placement period (time 1-6 months) as the time-dependent outcome variable, and the total number of patient-handling activities during one dayshift as the time-independent determinant and time (exact number of days) as an additional determinant. The interaction of "patient-handling activities $\times$ gender" was examined; if not significant, the interaction term was removed from the model. In all the analyses, the baseline serum concentration of the outcome variable, body mass index (BMI), and gender were included in the model as time-independent determinants.

The Statistical Package for Interactive Data Analysis (SPIDA, version 6.05) was used for the GEE analyses. The Statistical Package for Social Sciences (SPSS for Windows, version 9.0) was used for the analysis of variance.

\section{Results}

\section{Baseline values}

The serum concentrations of PICP and CTx and the PICP : CTx ratio determined each month are shown for both groups in figure 2. An analysis of variance showed that the two groups did not differ with respect to the baseline serum concentrations of PICP $\left(\mathrm{F}_{1.56}=0.01\right.$, $\mathrm{P}=0.95)$ and CTx $\left(\mathrm{F}_{1.56}=1.80, \mathrm{P}=0.19\right)$, and the PICP : CTx ratio $\left(\mathrm{F}_{1.56}=1.69, \mathrm{P}=0.19\right)$.

\section{Comparison of the exposed and reference groups}

The results of the GEE analyses on the effect of group on the serum concentrations of PICP and CTx and the PICP : CTx ratio during the 6-month work-placement period are presented in table 2 . For PICP, the time
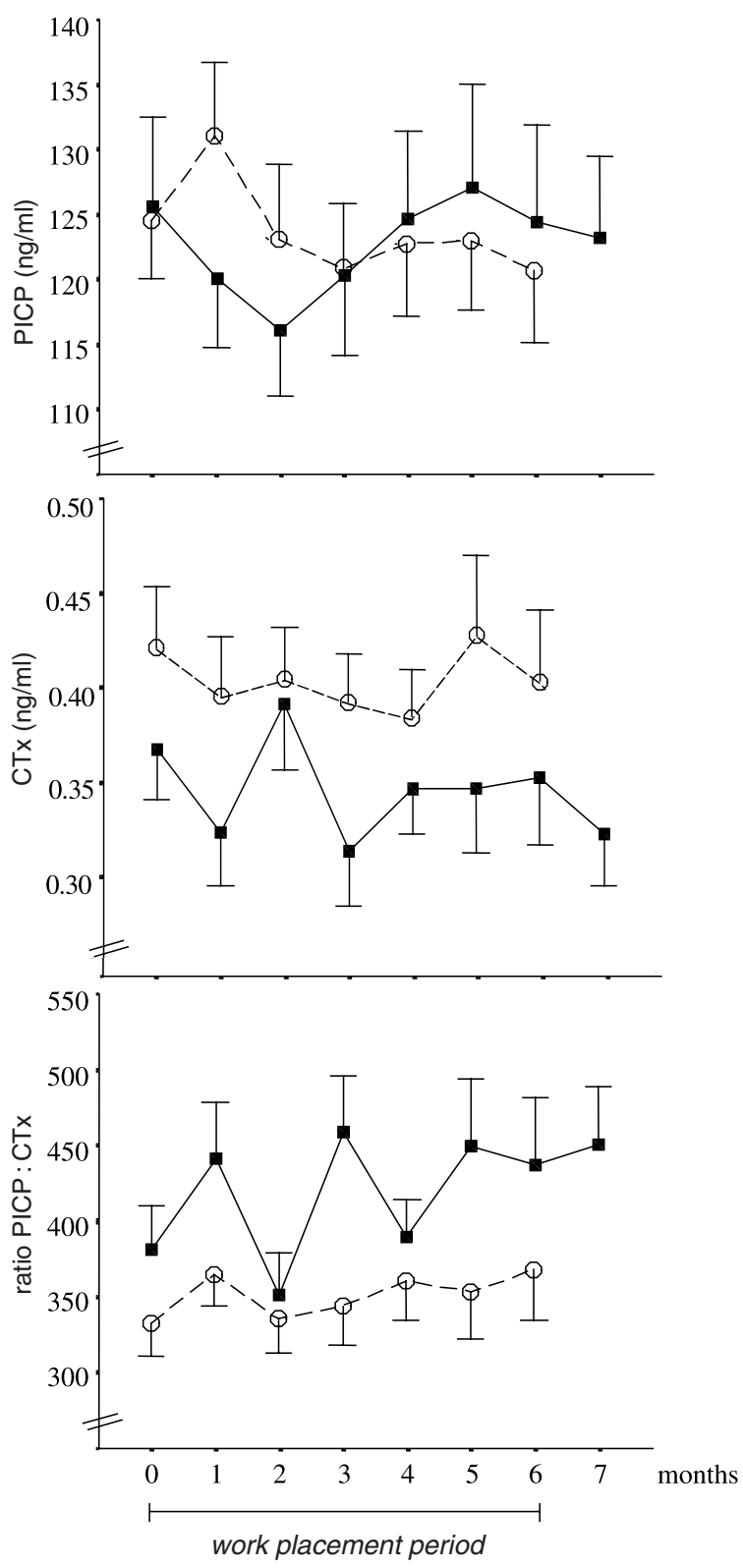

Figure 2. Mean ( \pm 1 standard error of the mean) serum concentrations of the propeptide of type I collagen (PICP) and the carboxyterminal telopeptide region of type I collagen (CTX) and the PICP: CTx ratio for the exposed group ( $\square)$ and the reference group (O). 
Table 2. Regression coefficients and 95\% confidence intervals $(95 \% \mathrm{Cl})$ of the generalized estimating equations with serum concentrations of propeptide of type I collagen (PICP), carboxyterminal telopeptide region of type I collagen (CTx), and the PICP:CTx ratio measured once a month during the 6-month workplacement period as the outcome variables and group as the determinant, adjusted for time, gender, body mass index (BMI), and interaction time $\times$ group if significant $(\mathrm{N}=60)$.

\begin{tabular}{|c|c|c|}
\hline & B & $95 \% \mathrm{Cl}$ \\
\hline \multicolumn{3}{|l|}{ PICP } \\
\hline Intercept & 94.4 & $44.3-144.5$ \\
\hline Group a & -14.0 & $-24.2-\quad-3.9$ \\
\hline Baseline PICP & 0.7 & $0.6-\quad 0.8$ \\
\hline Time & -0.2 & $-0.3--0.0$ \\
\hline Gender ${ }^{\mathrm{b}}$ & -14.4 & $-29.7-1.0$ \\
\hline BMI & -0.3 & $-1.5-0.9$ \\
\hline Time $\times$ group & 0.1 & $0.0-\quad 0.2$ \\
\hline \multicolumn{3}{|l|}{ CTX } \\
\hline Intercept & 0.9 & $0.9-1.6$ \\
\hline Group $^{a}$ & -0.1 & $-0.1-0.0$ \\
\hline Baseline Ctx & 0.4 & $0.3-0.6$ \\
\hline Time & 0.0 & $-0.0-0.0$ \\
\hline Gender ${ }^{b}$ & -0.3 & $-0.5--0.1$ \\
\hline $\mathrm{BMI}$ & -0.0 & $-0.0-\quad 0.0$ \\
\hline \multicolumn{3}{|l|}{ PICP/CTX } \\
\hline Intercept & -404.4 & $-7299.9--79.0$ \\
\hline Groupa & 63.6 & $13.3-113.9$ \\
\hline Baseline ratio PICP: Ctx & 0.3 & $0.2-\quad 0.4$ \\
\hline Time (days) & 0.2 & $-0.3-0.5$ \\
\hline Gender ${ }^{b}$ & 149.3 & $51.8-246.7$ \\
\hline BMI $\left(\mathrm{kg} / \mathrm{m}^{2}\right)$ & 13.2 & $4.0-22.4$ \\
\hline
\end{tabular}

a Group code: reference group=1, exposed group $=2$.

${ }^{\mathrm{b}}$ Gender code: $\mathrm{men}=1$, women $=2$.

course of the serum concentrations differed for the two groups, as indicated by the significant interaction between time and group $(\mathrm{P}=0.05)$. When adjusted for this interaction, the regression coefficient for group was significant $(\mathrm{P}=0.01)$. The regression coefficient for group was negative, the negative result indicating that the serum concentrations of PICP were lower in the exposed group than in the reference group. In the CTx model, the regression coefficient for group was also negative, but not significant $(\mathrm{P}=0.07)$. The PICP : $\mathrm{CTx}$ ratio was higher in the exposed group $(\mathrm{P}<0.01)$.

\section{Associations between patient-handling activities and biomarkers}

Table 3 shows the results of the GEE analyses on the associations between the serum concentrations of each of the biomarkers and the PICP: CTx ratio during the work-placement period and the observed number of patient-handling activities on a representative dayshift in that period. In the analyses of all three biomarker parameters, the interaction "gender $\times$ number of patienthandling activities" was significant (PICP, $\mathrm{P}=0.05$; $\mathrm{CTx}$, $\mathrm{P}<0.01$; PICP: CTx ratio, $\mathrm{P}<0.01)$ and therefore indicat-
Table 3. Regression coefficients and $95 \%$ confidence intervals $(95 \% \mathrm{Cl})$ of the generalized estimating equations with serum concentrations of propeptide of type I collagen (PICP), carboxyterminal telopeptide region of type I collagen (CTx), and the PICP:CTx ratio measured once a month during the 6-month workplacement period in the exposed group as the outcome variables and the frequency of patient-handling activities in one shift as the determinant, adjusted for time, gender, body mass index (BMI), baseline value of the determinant and interaction gender $\times$ patienthandling activites $(\mathrm{N}=30)$.

\begin{tabular}{|c|c|c|}
\hline & B & $95 \% \mathrm{Cl}$ \\
\hline \multicolumn{3}{|l|}{ PICP } \\
\hline Intercept & 86.9 & $9.6-164.2$ \\
\hline Patient handling & -5.1 & $-10.2-\quad-0.0$ \\
\hline Baseline PICP & 0.7 & $0.6-\quad 0.8$ \\
\hline Time & -0.1 & $-0.0-\quad-0.2$ \\
\hline Gender ${ }^{\mathrm{a}}$ & -26.3 & $-45.6-\quad-6.9$ \\
\hline BMI & -0.3 & $\begin{array}{ll}-3.0- & 2.4\end{array}$ \\
\hline Gender $\times$ patient handling a & 2.6 & $0.0-\quad 5.2$ \\
\hline \multicolumn{3}{|l|}{ CTX } \\
\hline Intercept & 1.3 & $0.9-\quad 1.6$ \\
\hline Patient handling & -2.5 & $-4.1-\quad-0.9$ \\
\hline Baseline Ctx & 0.3 & $0.1-\quad 0.6$ \\
\hline Time & 0.0 & $-0.0-\quad 0.0$ \\
\hline Gender a & -0.4 & $-0.4-\quad-0.3$ \\
\hline BMI & 0.0 & $-0.0-\quad 0.0$ \\
\hline Gender $\times$ patient handling a & 1.2 & $0.4-$ \\
\hline \multicolumn{3}{|l|}{$\mathrm{PICP} / \mathrm{CTX}$} \\
\hline Intercept & -856.4 & $-1228.7--484.1$ \\
\hline Patient handling & 20.9 & $8.3-33.5$ \\
\hline Baseline ratio PICP/Ctx & 0.3 & $0.1-\quad 0.5$ \\
\hline Time & 0.1 & $-0.4-$ \\
\hline Gender ${ }^{\mathrm{a}}$ & 259.6 & $200.6-318.5$ \\
\hline BMI & 29.4 & $16.0-42.8$ \\
\hline Gender $\times$ patient handling a & -9.9 & $-16.4-\quad-3.5$ \\
\hline
\end{tabular}

a Gender code: men=1, women=2.

ed differences in the effects of the number of patienthandling activities on the serum concentrations of the biomarkers between the men and women. When adjusted for these interaction effects, the regression coefficients for patient handling in the models of PICP and CTx and the PICP:CTx ratio were significant (PICP, $\mathrm{P}=0.05$; CTx, $\mathrm{P}<0.01$; PICP : CTx ratio, $\mathrm{P}<0.01)$. For PICP and CTx the coefficient was negative, whereas for the PICP : CTx ratio a positive coefficient was found.

\section{Discussion}

In this study a start was made towards exploring potential biomarkers for the effects of occupational physical back load. No valid serum markers specific for metabolic alterations in spinal structures are available. Therefore, PICP and CTx as validated assays for markers of components that are important constituents of, but not specific for, spinal tissues were considered potential 
biomarkers. Nurses were studied since their work, and especially their tasks involving manual handling of patients, has been characterized as hazardous with respect to low-back disorders $(4,25,26)$. However, nursing work also involves physical loading of the whole body. Since the serum concentrations of PICP and CTx are not specific for spinal tissues, the results of this study provide information on the effects of physical workload in general, and discernment of the relative contributions of the specific sites in the human body is not possible.

The longitudinal design of this study with monthly repeated measurements enabled an analysis of the temporal trend of the biomarkers. Biological variation of the biomarkers is considerable. In the statistical analyses adjustments were made for the baseline values of the biomarkers. Despite considerable intra- and interindividual variability, serial comparison of the values of the exposed and reference subjects indicated that the effects of exposure exceeded the normal biological variability. As the reference group had no occupational exposure, there was a considerable contrast in exposure to physical load between the two study groups. The rationale for the choice of student nurses as the study population was the relative lack of occupational load history. Furthermore, the population consisted of young, healthy subjects and therefore limited the confounding effects of degenerative connective tissue disorders.

Serum concentrations of biomarkers of type I collagen metabolism were found to be different in subjects exposed to physically demanding work when compared with unexposed subjects. Monthly repeated measurements of healthy young student nurses exposed to physical workload for a period of 6 months showed lower serum concentrations of the marker of type I collagen anabolism (PICP) when compared with the results of the reference group. The concentrations of the marker of catabolism (CTx) also tended to be lower, but this difference was not statistically significant. The PICP : CTx ratio, on the other hand, was significantly higher for the exposed subjects. Thus, in the 6-month exposure period, type I collagen metabolism was more anabolic in the exposed group. Within the exposed group, longitudinal analyses on associations between biomarkers during the work-placement period and number of patient-handling activities on a workday revealed a picture similar to that of the analyses on the effect of group (ie, higher exposure was associated with lower concentrations of PICP and CTx but with a higher PICP : CTx ratio). Considering the fact that the longitudinal design and the selection of the study population confined the effects of potential confounders, the conclusion that the differences in biomarker concentrations can be ascribed to the effects of physical workload is a plausible one. In healthy connective tissues, the cells respond to mechanical load by increased synthesis of collagen. This adaptive remodeling serves to strengthen the tissue to withstand higher forces (9). As already stated, the nonspecificity of the biomarkers together with the study design does not allow discernment of the relative contributions of connective tissues at specific sites of the human body. Nevertheless, it can be hypothesized that loading of the spinal structures played an important role in the differences in biomarker concentrations found in this study. The workplace observations provided only crude exposure measures, but from biomechanical studies it is known that in patient-handling activities especially the spinal structures are subjected to high compression and shear forces (26). Experiments on cadaver spines and animal studies have shown that exposure to these forces was associated with increased collagen synthesis in intervertebral discs (27-29). Most studies have focused on intervertebral discs since matrix changes and structural damage to this tissue are considered main features in the association between load and back disorders. However, adaptive remodeling responses also occur in other spinal structures, as has been illustrated by the finding of dense vertebrae in weightlifters and osteophytes around the margins of vertebral bodies in people involved in heavy manual labor (8).

This study was not able to show a temporal correlation between exposure and effect. Changes in exposure were assessed crudely, but the fact that the exposed group was unexposed at the start of the study, and spent a lot of time observing senior nurses during the first months of the study period, suggests an increase in exposure during the first months, which stabilized in the third month. However, in the reference as well as the exposed groups, the biomarker concentrations did not change significantly in time during the study period. PICP was an exception, as the time course differed significantly between the groups, but, when the time course of PICP was analyzed separately for each group, the changes in time were not significant in either group. Blood concentrations of type I collagen metabolic markers probably reflect the actual status of type I collagen metabolism (15). With respect to the time frame, it has been shown that, in response to a single bout of strenuous exercise (ie, running a marathon), type I collagen synthesis increased, reaching a peak after 3 days and returning to the baseline value 5 days after the run (16). The current study was not designed to assess the possible effects of acute changes in physical load on collagen metabolism. The purpose of the monthly repeated measurements of the biomarkers was to provide information on changes in the state of the tissues. The state of the tissue and the level of adaptation determine the response in collagen metabolism. Degradation mainly occurs 
when the load exceeds the strength of the tissue (15). The serum concentrations of the student nurses suggested that the level of physical load did not cause enhanced degradation in the 6-month study period, but merely yielded adaptive remodeling of the tissues. It would be interesting to assess follow-up measures for several years in high-risk occupations to investigate the long-term effects of physical load. In addition, a comparison of the responses in newly exposed workers with those of workers who have been exposed for years may provide useful information on the tissue responses to physical load.

The results of this exploratory study showed that serum concentrations of PICP and CTx and the PICP : CTx ratio are associated with exposure to physically demanding work. Although the relative contribution of back loading could not be determined, these results may provide a productive starting point for further research. For the potential biomarkers to be useful in identifying relevant load parameters and assessing biologically effective doses, studies are needed on aspects like the biological relevance and individual doseresponse relationships. Hence future studies should, for instance, combine biomarkers of collagen synthesis and degradation with imaging studies on molecular changes in specified tissues on one hand and with biomechanical models estimating forces on the spinal structures on the other. Furthermore, ongoing advancements in biochemical technology may enhance the development and validation of valid biomarkers for the effects of back load. Recent studies reported on increased knowledge and the development of more sophisticated assays for assessing bone and cartilage metabolism (30-32). This progress enhances the possibilities of obtaining tissue-specific information. In combination with assays for proteoglycan components or type II collagen metabolites, PICP and CTx may provide a more complete picture of tissue responses to physical load.

\section{Acknowledgments}

We thank Allard van der Beek for his contribution to the statistical analyses and his comments on the text. Furthermore we are grateful to Sijmen Kuiper and Suzan van Damme for performing the laboratory analyses.

\section{References}

1. Bernard B, editor. Musculoskeletal disorders and workplace factors: a critical review of epidemiologic evidence for work- related musculoskeletal disorders of the neck, upper extremity, and low back. Cincinnati (OH): US Department of Health and Human Services, National Institute for Occupational Safety and Health, 1997.

2. Burdorf A, Sorock G. Positive and negative evidence of risk factors for back disorders. Scand J Work Environ Health 1997;23:243-56.

3. Hoogendoorn W, van Poppel M, Bongers P, Koes B, Bouter L. Systematic review of psychosocial factors at work and private life as risk factors for back pain. Spine 2000;25:2114-25.

4. Kuiper J, Burdorf A, Verbeek J, Frings-Dresen M, Van der Beek A, Viikari-Juntura E. Epidemiologic evidence on manual materials handling as a risk factor for back disorders: a systematic review. Int J Ind Ergon 1999;24:389-404.

5. Waddell G, Burton A. Occupational health guidelines for the management of low back pain at work: evidence review. Occup Med 2001;51:124-35.

6. Van der Beek AJ, Frings-Dresen MHW. Assessment of mechanical exposure in ergonomic epidemiology. Occup Environ Med 1998;55:291-9.

7. Keyserling W. Workplace risk factors and occupational musculoskeletal disorders, part 1: a review of biomechanical and psychophysical research on risk factors associated with lowback pain. Am Ind Hyg Assoc J 2000;61:39-50.

8. Adams M, Dolan P. Recent advances in lumbar spinal mechanics and their clinical significance. Clin Biomech 1995;10:3-19.

9. Adams M, Dolan P. Could sudden increases in physical activity cause degeneration of intervertebral discs? Lancet 1997;350:734-5.

10. Risteli J, Risteli L. Assays of type I procollagen domains and collagen fragments: problems to be solved and future trends. Scand J Clin Lab Invest Suppl 1997;227:105-13.

11. Brahm H, Piehl-Aulin K, Ljunghall S. Bone metabolism during exercise and recovery: the influence of plasma volume and physical fitness. Calcif Tissue Int 1997;61:192-8.

12. Brahm H, Piehl-Aulin K, Saltin B, Ljunghall S. Net fluxes over working thigh of hormones, growth factors and biomarkers of bone metabolism during short lasting dynamic exercise. Calcif Tissue Int 1997;60:175-80.

13. Fujimura R, Ashizawa N, Watanabe M, Mukai N, Amagai H, Fukubayashi THK, et al. Effect of resistance exercise training on bone formation and resorption in young male subjects assessed by biomarkers of bone metabolism. J Bone Miner Res 1997;12:656-62.

14. Kristoffersson A, Hultdin J, Holmlund I, Thorsen K, Lorentzon R. Effects of short-term maximal work on plasma calcium, parathyroid hormone, osteocalcin and biochemical markers of collagen metabolism. Int J Sports Med 1995;16:145-9.

15. Langberg H, Skovgaard D, Petersen L, Bulow J, Kjaer M. Type I collagen synthesis and degradation in peritendinous tissue after exercise determined by microdialysis in humans. J Physiol 1999;521(pt 1):299-306.

16. Langberg H, Skovgaard D, Asp S, Kjaer M. Time pattern of exercise-induced changes in type I collagen turnover after prolonged endurance exercise in humans. Calcif Tissue Int 2000;67:41-4.

17. Thorsen K, Kristoffersson A, Hultdin J, Lorentzon R. Effects of moderate endurance exercise on calcium, parathyroid hormone, and markers of bone metabolism in young women. Calcif Tissue Int 1997;60:16-20.

18. Virtanen P, Viitasalo JT, Vuori J, Vaananen K, Takala TE. Effect of concentric exercise on serum muscle and collagen markers. J Appl Physiol 1993;75:1272-7. 
19. Hupli M, Hurri H, Luoto S, Risteli L, Vanharanta H, Risteli J. Low synthesis rate of type I procollagen is normalized during active back rehabilitation. Spine 1997;22:850-4.

20. Frings-Dresen M, Kuijer P. The TRAC-system: an observation method for analyzing work demands at the workplace. Saf Sci 1995;21:163-5.

21. De Zwart B, Broersen J, Van der Beek A, Frings-Dresen M, Van Dijk F. Occupational classification according to work demands: an evaluation study. Int J Occup Med Environ Health 1997;10:283-95.

22. Rosenquist C, Fledelius C, Christgau S, Pedersen B, Bonde M, Qvist P, et al. Serum crossLap one step ELISA: first application of monoclonal antibodies for measurement in serum of bone-related degradation products from C-terminal telopeptides of type I collagen. Clin Chem 1998;44:2281-9.

23. Liang K-Y, Zeger S. Longitudinal data analysis using generalized linear models. Biometrika 1986;73:13-22.

24. Twisk J. Different statistical models to analyze epidemiological observational longitudinal data: an example from the Amsterdam growth and health study. Int J Sports Med 1997;18:216-24.

25. Lagerström M, Hansson T, Hagberg M. Work-related lowback problems in nursing [review]. Scand J Work Environ Health 1998;24:449-64.

26. Marras W, Davis K, Kirking B, Bertsche P. A comprehensive analysis of low-back disorder risk and spinal loading during the transferring and repositioning of patients using different techniques. Ergonomics 1999;42:904-26.

27. Hutton W, Toribatake Y, Elmer W, Ganey T, Tomita K, Whitesides $\mathrm{T}$. The effect of compressive force applied to the intervertebral disc in vivo: a study of proteoglycans and collagen. Spine 1998;23:2524-37.

28. Hutton W, Elmer W, Boden S, Hyon S, Toribatake Y, Tomita $\mathrm{K}$, et al. The effect of hydrostatic pressure on intervertebral disc metabolism. Spine 1999;24:1507-15.

29. Hutton W, Ganey T, Elmer W, Kozlowska E, Ugbo J, Doh E$\mathrm{S}$, et al. Does long-term compressive loading on the intervertebral disc cause degeneration? Spine 2000;25:2993-3004.

30. Garnero P, Piperno M, Gineyts E, Christgau S, Delmas PD, Vignon E. Cross sectional evaluation of biochemical markers of bone, cartilage, and synovial tissue metabolism in patients with knee osteoarthritis: relations with disease activity and joint damage. Ann Rheum Dis 2001;60:619-26.

31. Otterness IG, Weiner E, Swindell AC, Zimmerer RO, Ionescu M, Poole AR. An analysis of 14 molecular markers for monitoring osteoarthritis:relationship of the markers to clinical end-points. Osteoarthritis Cartilage 2001;9:224-31.

32. Young-Min S, Cawston T, Griffiths I. Markers of joint destruction: principles, problems and potential. Ann Rheum Dis 2001; 60:545-9.

Received for publication: 6 August 2001 